\title{
Cidadania, relações étnico-raciais e educação: desafios e potencialidades do ensino de Ciências
}

Douglas Verrangia

Petronilha Beatriz Gonçalves e Silva

Universidade Federal de São Carlos

\section{Resumo}

Em meio às discussões sobre direitos humanos, cidadania e educação, o presente artigo procura contribuir para o entendimento de desafios e potencialidades do ensino de Ciências no contexto de uma formação para a cidadania plena. 0 objetivo do texto é articular cidadania, a educação das relações étnico-raciais e o ensino de Ciências, tirando dessa articulação considerações, temáticas e questões relativas a formas pelas quais o ensino de Ciências pode promover a educação das relações étnico-raciais, entendida enquanto direito humano fundamental. Partindo de referências teórico-metodológicas e de dados empíricos coletados em duas pesquisas, foram identificados cinco grupos de temáticas e questões que podem ser abordadas no ensino de Ciências a fim de promover relações étnico-raciais éticas entre estudantes. Esses grupos são: a) impacto das Ciências Naturais na vida social e racismo; b) superação de estereótipos, valorização da diversidade e Ciências Naturais; c) África e seus descendentes e o desenvolvimento científico mundial; d) Ciências, mídia e relações étnico-raciais, e) conhecimentos tradicionais de matriz africana e afro-brasileira e Ciências. Para além de proclamar direitos, ressalta-se a necessidade de viabilizar sua efetivação e promover processos de formação de professores comprometidos com a educação de cidadãos críticos e engajados em lutas por equidade social. Por meio da análise empreendida, esperamos contribuir para o fomento do debate e da pesquisa sobre o papel do ensino de Ciências na formação de cidadãos, tendo em vista a construção de relações sociais positivas e o engajamento em lutas por eliminação de quaisquer formas de desigualdade social e de discriminação.

\section{Palavras-chave}

Formação para cidadania - Educação das relações étnico-raciais - Ensino de ciências. 


\title{
Citizenship, ethnical-racial relationships and education: challenges and opportunities in the teaching of Sciences
}

\author{
Douglas Verrangia \\ Petronilha Beatriz Gonçalves e Silva \\ Universidade Federal de São Carlos
}

Contact:

Douglas Verrangia

Univ. Fed. São Carlos - Araras

Rod. Anhanguera, km 174-SP 330

13600-970 - Araras - SP

E-mail: douglas@cca.ufscar.br

\begin{abstract}
Set amidst the discussions about human rights, citizenship, and education this article wants to contribute to the understanding of the challenges and opportunities of the teaching of Sciences within the context of a formation for full citizenship. The aim of the text is of articulating citizenship, ethnical-racial relationships in education, and the teaching of Sciences, extracting from such articulation considerations, themes and issues related to the forms in which the teaching of Sciences can promote the education of ethnical-racial relationships understood as a fundamental human right. Staring from theoretical-methodological references and empirical data collected in two studies, five groups of themes and issues were identified that could be approached in the teaching of Sciences with the purpose of promoting ethical ethnical-racial relationships amongst students. These groups are: a) the impact of Natural Sciences to social life and racism; b) the overcoming of stereotypes, valuation of diversity and Natural Sciences; c) Africa and her descendents and the world's scientific development; d) Sciences, media and ethnicalracial relationships; e) traditional knowledge of African and AfroBrazilian origin and the Sciences. Apart from proclaiming rights, we highlight the need to make their implementation possible and to promote teacher education processes committed to the formation of critical citizens engaged with the struggle for social equity. Through the analysis carried out here we hope to have contributed to foster the debate and research on the role of the teaching of Sciences in the formation of citizens, with a view to create positive social relations and the commitment to the struggle to eradicate every form of social inequality and discrimination.
\end{abstract}

\section{Keywords}

Education for citizenship - Education for ethnical-racial relations - Teaching of Sciences. 
0 presente artigo busca articular a educação das relações étnico-raciais e o ensino de Ciências em um contexto de formação para a cidadania. De tal articulação, tiram-se considerações, temáticas e questões relativas a formas pelas quais o ensino de Ciências pode promover a educação das relações étnico-raciais, entendida enquanto direito humano fundamental, exposto na Lei 9.394/1996, de Diretrizes e Bases da Educação Nacional, complementada pelo Parecer CNE/CP 003/04, ambos os textos discutidos mais adiante.

As referidas temáticas e questões são oriundas de reflexão e articulação entre as áreas de ensino de Ciências e de estudos sobre relações étnico-raciais e foram identificadas a partir de diferentes fontes: a) literatura nos campos de estudos abordados; b) conversas informais e entrevistas com docentes de Ciências na educação básica que participaram de cursos de formação continuada ${ }^{1}$ ministrados por um dos autores deste artigo; c) entrevistas com docentes de Ciências Naturais que participaram de uma pesquisa de doutorado finalizada. Além dessas fontes, é importante citar estudos e debates transcorridos no contexto acadêmico dos autores, apresentações da temática deste artigo junto a estudantes de ciências biológicas e em reuniões científicas de âmbito nacional e internacional ${ }^{2}$.

A partir dos dados e informações coletados nas diferentes oportunidades mencionadas, chegaram-se às temáticas tratadas neste artigo, que se valeu da seguinte indagação provocadora: "Que contribuições para a educação das relações étnico-raciais e para a formação da cidadania o ensino de Ciências pode trazer?".

Partindo de tal questão, identificaramse cinco grupos de temáticas e questões: a) impacto das Ciências Naturais na vida social e racismo; b) superação de estereótipos, valorização da diversidade e Ciências Naturais; c) África e seus descendentes e o desenvolvimento científico mundial; d) Ciências, mídia e relações étnico-raciais, e) conhecimentos tradicionais de matriz africana e afro-brasileira e Ciências.

No intuito de fundamentar e situar as mencionadas temáticas e questões em um con- texto teórico-metodológico, apresentam-se, em seguida, entendimentos centrais relativos à cidadania, ensino de Ciências e às relações étnico-raciais na sociedade brasileira.

\section{Cidadania e ensino de Ciências no Brasil}

Inicialmente é necessário esclarecer que, neste texto, se entende o ensino de Ciências como sendo as práticas escolares dedicadas a ensinos e aprendizagens de conhecimentos científicos produzidos no âmbito das Ciências Naturais. No sistema de ensino formal, estas ciências são tratadas sob a forma de disciplinas, a saber: Ciências e/ou Ciências Naturais, no ensino fundamental; Biologia, Física e Química, no ensino médio e em algumas escolas privadas no ensino fundamental. Neste trabalho, damos ênfase especificamente ao ensino e aprendizagem no contexto escolar, não nos atendo, propositadamente, a outros ambientes, como museus, zoológicos, parques, contato com a mídia, particularmente com meios de divulgação científica. É importante frisar que todos os ambientes mencionados promovem o acesso a conhecimentos científicos, como bem aponta Krasilchik (1987).

Relativamente ao ensino de Ciências, Krasilchik (1987), Melo (2000) e Santos (2006) mostram que, nos anos 1950-1960, se enfatizava o método científico, priorizando, para a aprendizagem de conteúdos conceituais, a participação de estudantes em atividades de laboratório. Nos anos 1970, esses autores indicam o surgimento do movimento "ciência, tecnologia e sociedade" (CTS) e a valorização da relação entre conhecimento científico, desenvolvimento tecnológico e vida social. Apontam também que, em consequência do movimento

1. Provocadas nas atividades do "Programa São Paulo: Educando pela diferença para a igualdade", curso de capacitação para docentes de educação básica que fez parte do programa de políticas de ações afirmativas do governo do Estado de São Paulo nos anos de 2004, 2005 e 2006. Foram capacitados cerca de 14 mil docentes da rede pública estadual de ensino. 2. IV Congresso Brasileiro de Pesquisadores Negros, XIII Jornadas de Jóvenes Pesquisadores de la AUGM - Tucumán, 2005 e Congreso Internacional EI Status de las Comunidades Afro-Latinas en las Américas - Buenos Aires, 2005. 
CTS e de outros fatores sociais, nos anos 1980 se inicia uma forte influência de referências construtivistas nas práticas pedagógicas e na pesquisa sobre tais práticas, que se verifica na contemporaneidade. Prosseguindo, os mencionados autores assinalam, nos anos 1990, a centralidade da discussão sobre as interações entre ensino de Ciências e formação para a cidadania, entendidas como reflexo do contexto sociopolítico da sociedade brasileira.

No contexto atual, cerca de vinte anos após o fim de uma ditadura militar, as práticas democráticas se consolidam e a noção de cidadania perpassa políticas públicas de educação e discursos sobre a sociedade. Coerentemente com tal contexto, a noção de cidadania perpassa também o ensino de Ciências e a produção de conhecimentos sobre este campo. Santos (2006), em texto intitulado "Ensino de Ciências e a ideia de cidadania”, destaca:

As atenções hoje da educação estão basicamente voltadas para a ideia de cidadania e para a formação de professores com novos perfis profissionais, mestres em condições de trabalhar com uma visão interdisciplinar da ciência, própria das múltiplas formas de se conhecer e intervir na sociedade hoje. (p. 1)

A ênfase nas interações entre ensino de Ciências e cidadania é amplamente sustentada pela legislação educacional vigente e pelos textos normativos que orientam o ensino de Ciências. Por exemplo, a Lei 9.394/1996, de Diretrizes e Bases da Educação Nacional, esclarece em seu artigo $2^{\circ}$ :

A educação, dever da família e do Estado, inspirada nos princípios de liberdade e nos ideais de solidariedade humana, tem por finalidade o pleno desenvolvimento do educando, seu preparo para o exercício da cidadania e sua qualificação para o trabalho. (Brasil, 1996, p. 1, grifo nosso)

Essa centralidade é manifesta também quando se apresentam as disposições gerais para a educação básica, no art. 22 da referida lei:
A educação básica tem por finalidades desenvolver o educando, assegurar-lhe a formação comum indispensável para o exercício da cidadania e fornecer-lhe meios para progredir no trabalho e em estudos posteriores. (Brasil, 1996, p. 7, grifo nosso)

As mencionadas disposições legais, de forma coerente, são reafırmadas quando se analisam orientações dirigidas a áreas específicas, como o ensino de Ciências (Santos, 2006; Santos; Bispo; Omena, 2005). Desta forma, os Parâmetros Curriculares Nacionais, na Introdução aos volumes dirigidos ao ensino fundamental e médio, no que diz respeito ao ensino de Ciências Naturais, apontam como um dos objetivos "que o aluno desenvolva competências que lhe permitam compreender o mundo e atuar como indivíduo e cidadão, utilizando conhecimentos de natureza científica e tecnológica” (Brasil, 1998).

Os mesmos Parâmetros Curriculares Nacionais para o Ensino de Ciências Naturais entendem cidadania:

[...] como participação social e política, assim como exercício de direitos e deveres políticos, civis e sociais, adotando, no dia-a-dia, atitudes de solidariedade, cooperação e repúdio às injustiças, respeitando o outro e exigindo para si o mesmo respeito. (Brasil, 1998, p. 7, grifos nossos)

Neste sentido, os PCN's propõem que os estudantes do ensino fundamental, para tornarem-se cidadãos, devem ser capazes de:

[...] conhecer e valorizar a pluralidade do patrimônio sociocultural brasileiro, bem como aspectos socioculturais de outros povos e nações, posicionando-se contra qualquer discriminação baseada em diferenças culturais, de classe social, de crenças, de sexo, de etnia ou outras características individuais e sociais. (Brasil, 1998, p. 7)

Em 2004, o Parecer CNE/CP 003/04 (Brasil, 2004) estabeleceu as "Diretrizes Curricula- 
res Nacionais para a Educação das Relações Étnico-Raciais e para o Ensino de História e Cultura Afro-Brasileira e Africana”, em decorrência da promulgação da Lei $10.639 / 03$, bem como da Indicação CNE/CP 02/2002, em que o Conselho Nacional de Educação se propunha a manifestar-se sobre a educação das relações étnico-raciais. A Lei 10.639/03 instituiu a obrigatoriedade do ensino de História e Cultura Afro-Brasileira e Africana no sistema de educação escolar brasileiro em todos os seus níveis.

Como se vê, a importância das relações sociais, e étnico-raciais, nos processos educativos é considerada, pela legislação educacional brasileira, com a finalidade de formação para a cidadania. Neste trabalho, entende-se, acompanhando Silva e Araújo-Oliveira (2004), que:

\section{[...] cidadãos são mulheres e homens que to- mando a história dos grupos a que pertencem nas mãos, empreendem luta para que todos, nas suas particularidades sejam reconhecidos, aceitos e respeitados, busquem garantias para participar das decisões que encaminharão os destinos da sua comunidade, da nação onde exercem sua cidadania, do continente onde vivem. (p. 6, grifos nossos)}

Embora orientadas por outras referências teóricas, Krasilchik e Marandino (2004), no livro Ensino de Ciências e cidadania, manifestam entendimento similar ao de Silva e Araújo-Oliveira (2004) referente ao papel das relações sociais na formação dos cidadãos. Krasilchik e Marandino (2004) apresentam como uma das competências necessárias para a formação de cidadãos críticos “ter consciência da importância da sua função no já citado aperfeiçoamento individual e das relações sociais" (p. 8, grifos nossos).

As leis e textos normativos mencionados, bem como os pesquisadores citados, apontam a importância das relações sociais na formação para a cidadania no âmbito escolar. 0 ensino de Ciências, como todos os componentes curriculares, é parte constitutiva desse processo e, portanto, deve contribuir para a formação de cidadãos e cidadãs que vivenciem e procurem produzir relações sociais éticas.

0 movimento social negro, em seus diversos grupos, vem, desde o início do século $\mathrm{XX}$, chamando a atenção para o fato de que não é suficiente pensar apenas em termos de relações sociais se estivermos empenhados na formação de cidadãos críticos e participantes (Silva, 2004). Tais grupos denunciam a necessidade de se atentar, principalmente no campo da educação, para as especificidades das relações étnico-raciais, posição sustentada pela legislação apresentada anteriormente e por diversos trabalhos científicos, como, por exemplo, o de Gomes e Silva (2002).

Nessa perspectiva, focalizamos, no presente artigo, as relações étnico-raciais enquanto imprescindiveis para a formação de cidadãos e cidadãs e tecemos considerações sobre as possíveis contribuições do ensino de Ciências neste contexto.

\section{Relações étnico-raciais e educação}

Entendem-se aqui, por relações étnicoraciais, aquelas estabelecidas entre os distintos grupos sociais, e entre indivíduos destes grupos, informadas por conceitos e ideias sobre as diferenças e semelhanças relativas ao pertencimento racial destes indivíduos e dos grupos a que pertencem. Relacionam-se ao fato de que, para cada um e para os outros, se pertence a uma determinada raça, e todas as consequências desse pertencimento. Em outras palavras, quando estamos face a face com outra pessoa, é inegável que seu fenótipo, cor da pele, penteado e forma de vestir-se desencadeiam, de nossa parte, julgamentos sobre quem é, o que faz e até o que pensa tal pessoa. Dessa forma, informados por estereótipos, se não estivermos atentos, podemos manifestar, por palavras e gestos, discriminação, desrespeito, desqualificação. Estes julgamentos decorrem de preconceitos. Pessoas negras têm sido vítimas deles. Não poucas vezes se ouve que pessoas "desta raça”, os negros, são feios, sujos, violentos ou preguiçosos. Cabe mencionar 
aqui que a palavra raça não se refere ao conceito biológico de raças humanas, amplamente rechaçado pelos conhecimentos científicos aceitos nos dias de hoje. Tal conceito se refere à construção social que envolve características físicas e culturais (Guimarães, 2003). No Brasil, tensas relações étnico-raciais são vividas, principalmente, entre negros e brancos ${ }^{3}$.

É inegável que se vive um momento importante para o combate à discriminação racial; fala-se sobre e discutem-se cada vez mais abertamente as tensas relações étnico-raciais vividas no Brasil.

Antes de continuar, cabe destacar que a preocupação com as distorções sociais causadas por relações étnico-raciais adversas para as pessoas negras é introduzida, entre os legisladores e nos sistemas de ensino, pela pressão exercida pelo Movimento Negro e por acordos internacionais assinados pelo governo brasileiro ${ }^{4}$. Tal pressão e acordos têm resultado em textos legais voltados à área de educação, como a já mencionada Lei 10.639/03 e o Parecer CNE/CP 003/04, que introduz no campo da educação o termo "educação das relações étnico-raciais". 0 referido Parecer precisa:

\section{[...] a educação das relações étnico-raciais} impõe aprendizagens entre brancos e negros, trocas de conhecimentos, quebra de desconfianças, projeto conjunto para construção de uma sociedade, justa, igual, equânime. (Brasil, 2004, p. 6)

Esse texto legal é dirigido aos sistemas de ensino - da educação infantil ao ensino superior - e a todos os "cidadãos comprometidos com a educação dos brasileiros” (Brasil, 2004, p. 2). 0 Parecer deixa claro que a promoção de relações étnico-raciais positivas é um dever de toda a sociedade, mas trata de estabelecer a função do sistema escolar nesse processo.

A educação das relações étnico-raciais refere-se a processos educativos que possibilitem às pessoas superar preconceitos raciais, que as estimulem a viver práticas sociais livres de discriminação e contribuam para que elas compreendam e se engajem em lutas por equidade social entre os distintos grupos étnico-raciais que formam a nação brasileira. Refere-se, também, a um processo educativo que favoreça que negros e não negros construam uma identidade étnico-racial positiva. Para tanto, é preciso que a história dos afro-brasileiros e dos africanos seja compreendida de forma não distorcida, o que inclui a valorização das significativas contribuições que eles deram para o desenvolvimento humano e, particularmente, para a construção da sociedade brasileira.

A escola não é a única instituição responsável pela educação das relações étnico-raciais, uma vez que o processo de se educar ocorre também na família, nos grupos culturais, nas comunidades, no convívio social proporcionado pelos meios de comunicação, entre outros. É importante ressaltar que a escola é um ambiente privilegiado para a promoção de relações étnico-raciais positivas em virtude da marcante diversidade em seu interior. É o entendimento do Movimento Negro, de educadores, crianças, jovens e adultos negros e também de muitos professores conscientes das práticas sociais levadas a cabo no cotidiano escolar, como bem têm mostrado os resultados de pesquisas, dentre as quais podem ser mencionadas Algarve (2004) e Andrade (2006).

As discussões acerca do papel da educação escolar nas relações étnico-raciais são convergentes com aquela sobre educação e cidadania, pois apresentam as especificidades e reivindicações de parte da população brasileira que luta pelo exercício pleno de sua cidadania. No Parecer CNE/CP 003/04 (Brasil, 2004),

3. Mas também entre negros, brancos, indígenas, judeus e entre tantas outras categorias criadas pela humanidade ao longo de sua história para diferenciar grupos sociais. Relações marcadas pela história de marginalização da população afrodescendente e do racismo que se transfigura e persiste, com distintas conotações, até nossos dias. Marcadas por mitos e ideologias, como o mito da democracia racial e a ideologia do branqueamento, tão bem analisados e superados, no campo da sociologia, por Munanga (2004), Guimarães (2003), entre outros.

4. Por exemplo, na III Conferência Mundial das Nações Unidas contra 0 Racismo, a Discriminação Racial, Xenofobia e Intolerância Correlata, em Durban - Árica do Sul. 
encontram-se subsídios para este entendimento. Por exemplo, no trecho em que o documento discrimina a quem é destinado, lê-se:

Destina-se também às famílias dos estudantes, a eles próprios e a todos os cidadãos comprometidos com a educação dos brasileiros, para nele buscarem orientações, quando pretenderem dialogar com os sistemas de ensino, escolas e educadores, no que diz respeito às relações étnico-raciais, ao reconhecimento e valorização da história e cultura dos afrobrasileiros, à diversidade da nação brasileira, ao igual direito à educação de qualidade, isto é, não apenas direito ao estudo, mas também à formação para a cidadania responsável pela construção de uma sociedade justa e democrática. (p. 2, grifos nossos)

Assim sendo, como a própria legislação educacional exige, cabe indagar: se o ensino de Ciências deve se ocupar da educação das relações étnico-raciais, de que forma o professor pode ensinar com essa orientação?

Segundo relatos de docentes, o ensino, de forma geral, e o de Ciências em particular, são entendidos como importantes para combater toda forma de discriminação.

Experiências de professores, ainda isoladas, e iniciativas de algumas escolas, por meio de projetos e atividades coletivas, têm interferido nas relações étnico-raciais que se desenrolam no cotidiano escolar (Verrangia, 2005; Algarve, 2004; Andrade, 2006). Em tais contextos pesquisados, é possível perceber que, dentre os componentes curriculares desenvolvidos nos projetos e atividades, o ensino de Ciências praticamente não tem sido abordado com a finalidade de educar relações étnico-raciais.

Como se percebeu no presente estudo, por meio do contato com docentes de Ciências em cursos de formação continuada, a maioria não consegue ver relações entre suas aulas e as atividades que a escola pretende implementar, no sentido de discutir e promover relações étnicoraciais positivas. Muitos procuram assumir uma postura de combate à discriminação em sala de aula, repreendendo discriminações e não discriminando. Porém, quando indagada acerca de atividades e conteúdos conceituais utilizados para abordar e promover relações étnico-raciais positivas entre os estudantes, a maioria se mostrou desorientada, despreparada e/ou insegura, com medo de "piorar a situação". Tal realidade é amplamente apontada pela bibliografia sobre educação e relações étnico-raciais (Gonçalves, 1985; Gomes; Silva, 2002).

As dificuldades apresentadas pelos docentes com que convivemos coincidem com as conclusões de Santos (2006) sobre as barreiras enfrentadas por professores de Ciências para promover uma formação para a cidadania. Segundo o autor mencionado, as três principais dificuldades referem-se:

[à] forma tradicional como a escola e alguns dos elementos que compõem os currículos estão organizados. Refiro-me às rígidas divisões das áreas de conhecimento em disciplinas estanques...;

[ao] receio que muitos professores têm, em particular os de Ciências, de discutir temas relacionados com valores...

[ao] distanciamento entre os conceitos científicos aprendidos em sala de aula e as questões científicas verdadeiramente relevantes para a vida das pessoas... (p. 2)

Santos (2006), porém, não discute, dentro da formação para a cidadania, o papel que assumem as relações étnico-raciais. Essa ausência foi verificada em quase toda a literatura sobre o ensino de Ciências que foi analisada no presente estudo. Verificou-se uma lacuna de trabalhos científicos acerca das dificuldades encontradas por docentes de Ciências com o objetivo de educar relações étnico-raciais em suas aulas. Também se verificou, por meio do convívio com docentes em cursos de formação continuada, que os poucos que se dedicam a tal intento enfrentam a falta de preparo e a inexistência de orientações específicas e de materiais didáticos adequados. 
Tal situação corrobora, por exemplo, os achados de Rosemberg, Bazili e Silva (2003), que depois de analisarem todas as pesquisas sobre racismo em livros didáticos produzidos entre $1953 \mathrm{e}$ 2003, apontam a inexistência de estudos sobre visões acerca da África e dos africanos e afrodescendentes em livros de Ciências. Cabe ressaltar que tais visões, certamente, incidem sobre as relações étnico-raciais vividas em sala de aula.

A fim de contribuir para mitigar essa ausência de referências específicas para um trabalho pedagógico objetivando a educação das relações étnico-raciais no ensino de Ciências, a seguir são descritos os resultados do presente estudo, temáticas e questões que podem ser objeto de um ensino de Ciências comprometido com tal objetivo.

\section{Ensino de Ciências e educação das relações étnico-raciais}

Em parte, as temáticas e questões aqui apresentadas foram elaboradas a partir da análise da literatura disponível nas áreas de educação, relações étnico-raciais e ensino de Ciências. A fim de contribuir para que o leitor possa aprofundar os estudos nessa literatura, optamos por mencionar, em notas de fim de texto, parte significativa da literatura consultada. As temáticas e questões em pauta foram identificadas tendo em vista a experiência de um dos autores como docente de Ciências e Biologia e em cursos de formação continuada de professores, assim como considerando a análise dos dados de entrevistas com oito professores de Ciências Naturais, no ensino fundamental, que participaram de um curso de formação continuada.

Reuniram-se as temáticas e questões em cinco grupos, a fim de sugerir procedimentos de trabalho no ensino de Ciências, bem como leituras para aprofundamento. Os mencionados grupos são: a) Impacto das Ciências Naturais na vida social e racismo; b) Superação de estereótipos, valorização da diversidade e Ciências Naturais; c) África e seus descendentes e o desenvolvimento científico mundial; d) Ciências, mídia e relações étnico-raciais; e) Conhecimentos tradicionais de matriz africana e afrobrasileira e Ciências. A seguir, apresentam-se as sugestões de trabalho e leituras.

\section{Impacto das Ciências Naturais na vida social e racismo}

Aqui, sugerem-se abordagens que, no ensino de Ciências, discutam o impacto do conhecimento científico sobre a vida social (Santos, 2004; 2006), levando em consideração o contexto histórico em que as teorias foram produzidas e apontando seus impactos no ideário social. É importante compreender e abordar esta questão por meio de uma análise que contemple dois aspectos: de um lado, os valores da sociedade que interferem na produção de conhecimentos científıcos e, de outro, a produção de conhecimentos científicos interferindo na construção de valores da sociedade.

Por exemplo, podem ser criadas atividades que explorem as relações entre os conhecimentos científıcos e a orientação de relações étnico-raciais desiguais, como o papel das teorias raciais do século XVIII e XIX e a fundamentação do chamado "racismo científico". Em tais atividades podem ser realizadas discussões sobre pesquisas, teorias e movimentos científicos que construíram conceitos como o biológico de raças humanas, ainda fortemente presente no ideário da população brasileira e que orienta tensas relações sociais. Da mesma forma, elas podem contemplar discussões e análises críticas sobre a importância histórica de teorias como a da evolução darwinista e a da hereditariedade mendeliana na formação de ideias sobre raça, miscigenação, etnia, gênero e sexo, normalidade e defeito, aptidão e inaptidão social etc. Neste mesmo sentido, ressalta-se a importância de se dimensionar e avaliar, de forma crítica, o papel de movimentos científicos como a eugenia na formação do imaginário social sobre raças, miscigenação e etnia, e a permanência de ideias criadas em seu contexto, do início do século XX ao período atual (Maio; Santos, 2006; Stepan, 2005; Domingues; Sá; Glick, 2003; Sacarrão, 1989). 
Outro importante aspecto que pode ser contemplado é a forma como o racismo e a exploração sistemática dos africanos e afrodescendentes produziram impactos que fragilizaram tais populações em diferentes contextos e países. Essa fragilização está intimamente relacionada a questões que devem ser abordadas no ensino de Ciências, como: a utilização de africanos e afrodescendentes em pesquisas científicas, principalmente no campo da medicina (Washington, 2006); a distribuição desigual do acesso aos recursos naturais e a exposição excessiva à poluição ambiental das populações afrodescendentes e indígenas, as chamadas "injustiças e racismos ambientais" (Lester; Allen; Hill, 2001), e os drásticos efeitos das mudanças globais sobre essas populações em diferentes partes do mundo (Mitchel, 2008).

\section{Superação de estereótipos, valorização da diversidade e Ciências Naturais}

Neste segundo grupo, destacam-se as abordagens que procurem, com base em conhecimentos produzidos pelas Ciências Naturais, promover a superação de estereótipos de inferioridade e valorizar a diversidade étnicoracial presente na sociedade. Para tanto, podem ser desenvolvidas atividades que contribuam para que os estudantes analisem criticamente a história do conceito biológico de raças humanas, rechaçado pela comunidade científica há mais de cinquenta anos. Neste contexto, seria importante esclarecer também o caráter social e ressignificado do conceito de raças humanas como é utilizado pela sociologia contemporânea (Munanga, 2004; Guimarães, 2003) e também pelos movimentos sociais, particularmente 0 Movimento Negro.

Tal trabalho pedagógico deve contar com uma análise crítica pautada em conhecimentos sólidos das Ciências Naturais (genética, evolução etc.) e também das Ciências Humanas (sociologia, antropologia etc.). Nesse sentido, podem ser abordados aspectos específicos da evolução humana, como a origem africana da humanidade, a formação dos grupos étnicoraciais e a evolução de caracteres como a cor da pele, entre outros (GTAAB, 1988; Andrade, 2002). Para atingir os objetivos esperados, esses temas devem ser abordados a fim de superar visões estereotipadas sobre as relações étnicoraciais, por meio de estímulo à crítica, pautada em conhecimentos científicos, às falsas ideias sobre superioridade/inferioridade biológica/ intelectual de certos grupos étnico-raciais em relação aos outros.

Outra sugestão é a abordagem da evolução humana de forma profunda, com a intenção de discutir e esclarecer a formação dos grupos étnico-raciais (Domingues; Sá; Glick, 2003). Sugere-se, neste contexto, a discussões sobre as diferenças físicas entre os diferentes grupos étnico-raciais e o papel da cultura em atribuir valores, negativos ou positivos, a tais características biológicas. Por meio de tal abordagem, propõe-se combater estereótipos, promovendo a distinção entre fatores biológicos e culturais presentes nessa complexa história evolutiva e valorizando a diversidade de formas físicas, tipo de cabelo, cor de pele, entre outras.

\section{África e seus descendentes e o desenvolvimento científico mundial}

Neste grupo, sugerem-se abordagens que apresentem e discutam a longa história da produção de conhecimentos no continente africano, que contribuíram para o desenvolvimento científico e tecnológico da humanidade, além da importância de africanos e afrodescendentes para as Ciências Naturais. Essas abordagens devem se ater à representação da população africana e afrodescendente, quase nunca positiva e menos ainda no campo das Ciências, no qual os cientistas negros raramente são reconhecidos e valorizados.

A história da produção de conhecimentos no continente africano, que dá sustentação à concepção de que ele é o berço das civilizações, pode ser resgatada na identificação e discussão 
de conceitos e práticas originados na África e que foram apropriados e reestruturados pelos povos gregos, persas, romanos, entre outros. Assim, é importante, no ensino de Ciências, promover atividades e discussões em que sejam contempladas as relações entre os povos africanos, incluindo os egípcios, os gregos e outros povos da Europa. Em tais práticas pode ser mencionado o costume da época, de cerca de 600 a 300 anos antes da era corrente, de enviar gregos como Pitágoras, Platão, Eudoxos e Democritus, durante longos períodos de tempo, para estudarem no Egito e aprenderem com essa civilização africana (Diop, 1991). Discussões como essa devem englobar a análise da origem do povo egípcio, oriundo da região etíope da África, suas características étnico-raciais e suas relações com outros povos africanos, como os núbios, os etíopes, os cuxitas e os axumitas.

No mesmo sentido, podem ser elaboradas atividades a fim de esclarecer os estudantes sobre as inúmeras contribuições africanas para o conhecimento científico mundial, que incluem, por exemplo: a medicina, a matemática, a metalurgia, a química e a tecnologia egípcia; a astronomia Dogon; a metalurgia e os conhecimentos sobre química da Núbia; os conhecimentos sobre cirurgia, imunização e obstetrícia dos povos Banyoro; a apresentação de cientistas africanos e afrodescendentes que contribuíram para a história da Ciência (como Cheik Anta Diop, na arqueologia; Lewis Howard Latimer, na física e na química; Benjamin Banneker, na matemática e na astronomia; Ernest Everett Just, na zoologia; Rebbeca Cole, na medicina e no cuidado infantil, entre outros). Uma análise muito rica e com informações ainda pouco divulgadas e, portanto, pouco conhecidas pode ser encontrada em uma série de trabalhos científicos (Diop, 1974; 1991; Nascimento, 1996; Finch III, 2001; Willians, 1987; Verrangia, 2005a).

Além dos aqui mencionados, há muitos outros conhecimentos no sentido de dimensionar as contribuições dos africanos e de seus descendentes para o desenvolvimento científico. Algumas informações essenciais podem ser en- contradas nas referências apresentadas e na vasta produção disponível na Internet, que aborda essas questões com informações confiáveis e bem ilustradas. Mas tais informações se encontram, em sua grande maioria, em língua inglesa e francesa, lacuna que pode ser preenchida por trabalhos de pesquisa e divulgação científica no Brasil que dimensionem a importância, ainda omitida na divulgação científica, dos afro-brasileiros no campo das Ciências Naturais.

\section{Ciências, mídia e relações étnico- raciais}

Neste grupo, destacam-se as abordagens que visem analisar criticamente as interações entre conhecimento científico, relações étnicoraciais e mídia. Essa análise perpassa a identificação e a caracterização do uso de conhecimentos científıcos pela mídia (revistas, jornais, televisão etc.) que, explicitamente ou não, procurem explicar ou justificar as relações étnico-raciais e outras relações sociais, como de gênero.

Sugere-se aqui a análise crítica da utilização dos conhecimentos científicos pela mídia na discussão, por exemplo, sobre políticas públicas, como as ações afirmativas, amplamente discutidas no atual momento. Para realizar a crítica sugerida, podem ser promovidas atividades que identifiquem e avaliem a veiculação de conhecimentos do campo da genética molecular, marcadores gênicos, no contexto de discussões sobre as chamadas "cotas raciais". Muitos jornais e revistas veicularam, no ano de 2007, pesquisas no campo da genética molecular que analisam, do ponto de vista biológico, a ancestralidade do povo brasileiro e de personalidades negras conhecidas. Essas pesquisas foram utilizadas por jornalistas em uma campanha contra as ações afirmativas, pautada na ideia de que, como a genética provaria, não existem raças humanas, portanto, não poderiam ser criadas classificações raciais para corrigir distorções históricas. 0 mais importante é que essas reportagens desconsideraram os aspectos sociais e culturais do conceito de raça, para construir um argumento objetivo, 
pautado em pesquisas científicas, contrário à política pública em pauta. Destaca-se, portanto, o papel do ensino de Ciências para formar pessoas capazes de compreender a manipulação e utilização de conhecimentos científicos, e da própria presença de cientistas, na construção de discursos midiáticos (Verrangia, 2008).

Sugere-se também a formulação de atividades que debatam o determinismo reducionista biológico do comportamento social. Para atingir o mencionado objetivo, pode-se analisar a veiculação pela mídia de informações simplistas que, amparadas fragilmente em conhecimentos da biologia evolutiva, desconsideram o papel da cultura e da aprendizagem sobre o comportamento humano. Esse tipo de informação estimula a formação de visões pautadas apenas em aspectos biológicos do comportamento social, acarretando preconceitos contra distintos grupos sociais, não entendidos em sua diversidade cultural, mas apenas enquanto grupo biológico. Nesse sentido, sugere-se a realização de atividades que abordem textos midiáticos, geralmente repletos de determinismos acerca das relações entre homens e mulheres, passando por temas como monogamia e poligamia; escolha de parceiros e atraçã $0^{5}$; orientação sexual e homossexualidade; comportamento sexual. Há também textos que abordam as interações entre Ciência e religião, por exemplo, procurando explicar a fé como resultado do processo evolutivo. Tais textos também podem ser analisados a fim de explicitar a utilização da Ciência pela mídia e os impactos dessa utilização no ideário social. Há um amplo campo de pesquisas sobre mídia e divulgação científica que trazem contribuições importantes para a formulação de atividades e abordagens com o intuito descrito aqui.

\section{Conhecimentos tradicionais de matriz africana e afro-brasileira e Ciências}

Sugere-se, neste último grupo, abordagens que examinem criticamente as interações entre o conhecimento científico ocidental e os conhecimentos tradicionais de raiz africana e afro-brasileira (Semali, 1999; Omolewa, 2007). É importante considerar, neste contexto, as discussões presentes em uma série de trabalhos de pesquisa que se dedicam a questões como a definição de Ciência e as especificidades do trabalho científico e o ensino de Ciências. Destes trabalhos, destacam-se aqueles que estudam o papel do conhecimento sobre epistemologia e história da Ciência na aprendizagem de conhecimentos científicos pelos estudantes.

Sugere-se a elaboração de atividades de ensino que abordem, sob a ótica cultural das populações tradicionais africanas e afrobrasileiras, o estudo: da vida; dos fenômenos naturais; dos animais; das plantas; das relações entre formas vivas e não vivas; da saúde; da produção de alimentos; entre outros. Tais atividades podem diferenciar tais conhecimentos daqueles produzidos pelas Ciências Naturais, mas com a intenção de valorizá-los enquanto patrimônio cultural mundial. Nesse contexto, podem ser apresentados aos estudantes fábulas, mitos, lendas e provérbios de matriz africana (Boateng, 1993) e afrodescendente que abordem os elementos já mencionados e outros que sejam estudados pelas Ciências Naturais, estimulando os estudantes a conhecerem mais detidamente as perspectivas culturais africanas e afro-brasileiras. Dois dos focos de tal ensino devem ser a valorização da diversidade cultural e o enriquecimento do entendimento sobre a função das Ciências, que envolve a busca por compreender a realidade.

No mesmo sentido, pode ser abordada a importância dos conhecimentos de comunidades tradicionais ${ }^{6}$ afro-brasileiras e ameríndias sobre ervas e plantas medicinais para a descoberta de princípios ativos e novos medicamentos, no contexto científico contemporâneo. Desta forma, pode-se abrir espaço para discutir co-

\footnotetext{
5. Por exemplo, a ideia de que os homens evoluíram para escolher sempre mulheres jovens e com determinado tipo de corpo, "escultural". 6. Quando nos referimos à tradição, neste texto, concordamos com Dussel (1974), que escreve: "A noção de tradição quer negar a noção de passiva repetição, imitação, recordação. A tradição é re-criação em seu duplo sentido: criar de novo e festejar celebrando o assumir desde o nada (a liberdade do filho) a história já constituída" (p. 187).
} 
nhecimentos tradicionais, inclusive de matriz africana e afro-brasileira, e conteúdos conceituais habitualmente abordados nas aulas, como os princípios ativos e a indústria farmacêutica. Nesse sentido, também poderiam ser descritos os processos de plantio e cultivo utilizados há séculos por comunidades remanescentes de quilombos e indígenas, e que mantêm a terra fértil, relacionando-os ao conceito atual de desenvolvimento sustentável (Guerra, 2004). Tais abordagens podem contribuir para a valorização dos povos que mantêm conhecimentos milenares vivos e para a ampliação da visão dos estudantes sobre o conhecimento científico.

\section{Conclusões}

Como se procurou mostrar, o ensino de Ciências, assim como todos os componentes curriculares, tem papel fundamental na promoção de relações sociais éticas entre os estudantes. No contato com docentes em cursos de formação continuada, pôde-se concluir que as abordagens do ensino de Ciências visando a educação das relações étnico-raciais podem contribuir para viabilizar processos educativos comprometidos com a formação para a cidadania. Pautando-se nas temáticas e questões apresentadas, atividades e projetos pedagógicos podem ser desenvolvidos e, segundo a análise dos docentes participantes de cursos de formação continuada, há um grande potencial em tais abordagens. Outra indicação desse potencial foi o grande interesse demonstrado por outros docentes de Ciências e estudantes do curso de Ciências Biológicas. Tal interesse, constatado em palestras e discussões organizadas junto a esses grupos, gerou o início de cursos sobre a temática.

Cabe ainda mencionar a necessidade identificada de que os cursos de formação de professores de Ciências ajudem a questionar os processos de seleção de conteúdos. Geralmente, no contexto escolar, tal seleção parte de conteúdos conceituais preestabelecidos, presentes em livros, textos e ementas para a definição de procedimentos de ensino. Analisando as interações entre ensino de Ciências e educação das relações étnico-raciais, verifica-se a necessidade de se inverter tal lógica. Para educar relações étnico-raciais é necessário definir de antemão valores e posturas a serem desenvolvidos pelos estudantes, para depois selecionar conteúdos conceituais e procedimentos de ensino adequados a tal propósito. Essa inversão de lógica pode contribuir também para a análise crítica e profunda de outro ponto apontado pela literatura como problemático no ensino de Ciências: a visão fragmentada do conhecimento científico abordado na escola (Santos, 2006). Ressalta-se, portanto, a necessidade de que os cursos de formação inicial e continuada de professores do ensino de Ciências discutam tanto a seleção de conteúdos e quanto a fragmentação do conhecimento científıco. Tais discussões tornam-se ainda mais essenciais quando os objetivos de tais cursos envolvem preparar professores que saibam lidar pedagogicamente com a diversidade étnico-racial (Gomes; Silva, 2002).

Finalmente, como está explícito na declaração Universal de Direitos Humanos: “a instrução será orientada no sentido do pleno desenvolvimento da personalidade humana... promoverá a compreensão, a tolerância e a amizade entre todas as nações e grupos raciais..." (Nações Unidas, 1948). Por meio da análise empreendida, esperamos contribuir para o fomento do debate e da pesquisa sobre o papel do ensino de Ciências na formação de cidadãos. Essa formação deve contemplar a construção de relações sociais positivas e o engajamento em lutas por eliminação de quaisquer formas de desigualdade social e de discriminação. 


\section{Referencias bibliográficas}

ALGARVE, V. Cultura negra na sala de aula: pode um cantinho de africanidades elevar a auto-estima de crianças negras e melhorar o relacionamento entre crianças negras e brancas? São Carlos, 2004, 274p. Dissertação (Mestrado)- Departamento de Metodologia de Ensino, Universidade Federal de São Carlos. 2004.

ANDRADE, P. S. Pertencimento étnico-racial e ensino de História. São Carlos, 2006, 179p. Dissertação (Mestrado)- Departamento de Metodologia de Ensino, Universidade Federal de São Carlos. 2006.

ANDRADE, R. M. T. Cor e Gen/e/te/ética. In: Paulo: Selo Negro, 2002, p. 119-132.

BOATENG, F. African traditional education: a tool for intergerational communication. In: ASANTE, M.; ASANTE, K. African culture: rhythms of unity. New Jersey: África World Press, 1993, p. 109-122.

BRASIL. Presidência da República. Casa Civil: subchefia para assuntos jurídicos. Lei nº 9.394, de 20 de dezembro de 1996: estabelece as diretrizes e bases da educação nacional. Brasília, 1996. Disponível em: <http://www.planalto.gov.br/CCIVIL_03/ LEIS/L9394.htm>. Acessado em: 6 mai. 2007.

Secretaria de Educação Fundamental. MEC/SEF. Parâmetros curriculares nacionais: Ciências Naturais. Brasília, 1998. Disponível em: <http://portal.mec.gov.br/seb/arquivos/pdf/ciencias.pdf>. Acessado em: 6 mai. 2007.

Conselho Nacional de Educação. Ministério da Educação. Diretrizes Curriculares Nacionais para a Educação das Relações Étnico-Raciais e para o Ensino de História e Cultura Afro-Brasileira e Africana. Brasília, 2004. Disponível em: <http://portal.mec. gov.br/cne/arquivos/pdf/003.pdf>. Acessado em: 6 mai. 2007.

DIOP, C. A. Civilization or barbarism: for an authentic anthropology. Chicago: Lawrence Hill Books, 1991. The african origin of civilization: myth or reality. Chicago: Lawrence Hills Books, 1974.

DOMINGUES, M. B.; SÁ, M. R.; GLICK, T. (Orgs.) A recepção do darwinismo no Brasil. Rio de Janeiro; Fiocruz, 2003.

DUSSEL, H. Para uma ética da libertação Latino-Americana. v. III: Erótica e Pedagógica. Piracicaba/São Paulo: Co-edição Edições Loyola/Editora UNIMEP, 1974.

FINCH III, C. S. The star of deep beginnings: the genesis of african science and technology. Georgia: Khenti, 2001.

GOMES, N. L.; SILVA, P. B. G. Experiências étnico-culturais para formação de professores. Belo Horizonte: Autêntica, 2002.

GONÇALVES, L. A. O. 0 silêncio: um ritual pedagógico a favor da discriminação racial. Belo Horizonte, 1985, p. 286. Dissertação (Mestrado) - Universidade Federal de Minas Gerais, Belo Horinzonte, 1985.

GTAAB. Cor e Gen/te. Ensino de Biologia: dos fundamentos às práticas, São Paulo, v. II, 1988. p. 32-43.

GUERRA, D. Cabeças (bem-)feitas: ciência e o ensinar-aprender ciências naturais num contexto pedagógico de afirmação cultural. In: Congresso Brasileiro de Pesquisadores Negros, 3., Caderno de Resumos, São Luís, p. 62, 2004.

GUIMARÃES, A. S. A. Como trabalhar com "raça" em sociologia. Educação e Pesquisa, São Paulo, v. 29, n. 1, p. 93-107, 2003.

KRASILCHIK, M. O professor e o currículo das Ciências. São Paulo: Edusp, 1987.

; MARANDINO, M. Ensino de ciências e cidadania. São Paulo: Moderna, 2004.

LESTER, J.; ALLEN, D.; HILL, K. Environmental injustice in the U.S.: myths and realities. Oxford: Westview Press, 2001.

MAIO, M. C.; SANTOS, R. V. Raça, ciência e sociedade. Rio de Janeiro: Fiocruz/CNBB, 2006.

MELO, M. do R. Ensino de Ciências: uma participação ativa e cotidiana. 2000. Disponível em: <http://www.rosamelo.hpg.ig.com. br/>. Acessado em: 6 mai. 2007.

MITCHEL, J. A. If the sun people die: climate change and the retention of african traditional spirituality: uncovering connections. In: CULTURAL ENDURANCE BETWEEN AFRICA, THE AMERICAS AND THE CARIBBEAN CONFERENCE. $9^{\text {th }}$, New York: Medgar Evers College - CUNY, 2008. p. 21.

MUNANGA, K. Rediscutindo a mestiçagem no Brasil: identidade nacional versus identidade negra. Belo Horizonte: Autêntica, 2004. 
NAÇÕES UNIDAS. Declaração Universal dos Direitos Humanos. Resolução 217A (III) da Assembleia Geral das Nações Unidas. 10 de dezembro de 1948. Disponível em: <http://www.onu-brasil.org.br/documentos_direitoshumanos.php>. Acessado em: 11 abr. 2007.

NASCIMENTO, E. L. Sankofa: matrizes africanas da cultura brasileira. Rio de Janeiro: Editora da Universidade do Estado do Rio de Janeiro, 1996.

OMOLEWA, M. Traditional african modes of education: their relevance in the modern world. International Review of Education, v. 53, p. 593-612, 2007.

ROSEMBERG, F.; BAZILI, C.; SILVA, P.V. B. Racismo em livros didáticos brasileiros e seu combate: uma revisão da literatura. Educação e Pesquisa, São Paulo, v. 29, n. 1, p. 125-146, jan./jun., 2003.

SACARRÃO, G. F. Biologia e sociedade. Lisboa: Europa-América, v. II, 1989.

SANTOS, B. S. (Org.). Conhecimento prudente para uma vida decente. São Paulo: Cortez, 2004.

Um discurso sobre as Ciências. 4. ed. São Paulo: Cortez, 2006.

SANTOS, P. O.; BISPO, J. S.; OMENA, M. L. R. A. 0 ensino de Ciências Naturais e cidadania sob a ótica de professores inseridos no programa de aceleração de aprendizagem da EJA - Educação de Jovens e Adultos. Ciência e Educação, Bauru, v. 11, n. 3, p. 411-426, 2005.

SANTOS, P. R. 0 ensino de Ciências e a idéia de cidadania. Revista Mirandum, ano X, n. 17, 2006. Disponível em: <http://www. hottopos.com/mirand17/prsantos.htm>. Acessado em: 11 abr. 2007.

SEMALI, L. Community as classrooms: dilemmas of valuing african indigenous literacy in education. International Review of Education, v. 45, n. 3/4, p. 305-319, 1999.

SILVA, P. B. G. Citizenship and education in Brasil: the contribution of indian peoples and blacks in the struggle for citizenship and recognition. In: BANKS, J. A. (Org.) Global perspectives: diversity and citizenship education. San Francisco, Jossey Bass (Ed.). v. 01, p. 185-217, 2004.

;ARAÚJO-OLIVEIRA, S. E. Cidadania, ética e diversidade: desafios para a formação em pesquisa. In: ENCUENTRO - CORREDOR DE LAS IDEAS DEL CONO SUR “SOCEIDADE CIVIL, DEMOCRACIA E INTEGRACIÓN", 6., Anais... Montevidéo, 2004, p. 127-144.

STEPAN, N. L. A hora da eugenia: raça, gênero e nação na América Latina. Rio de janeiro: Fiocruz, 2005.

VERRANGIA, D. A formação de docentes no combate ao racismo e a discriminacõos: aprender a conduzir a própria vida. In: JORNADAS DE JOVENS PESQUISADORES DA AUGM. NÚCLEO DISCIPLINAR EDUUCAÇÃO PARA A INTEGRAÇÃO, 13., 2005, Anais... San Miguel de Tucuman, 2005.

África de todos nós. Entrevistador: Paola Gentile. Revista Nova Escola, São Paulo, p. 42-49, nov. 2005a.

Impacto do conhecimento científico na vida social: ciência, tecnologia, sociedade e relações étnico-raciais. Olhar. Ciência Tecnologia e Sociedade, São Paulo, p. 47-56, 2008.

WASHINGTON, H. A. Medical apartheid: the dark history of medical experimentation on black americans from colonial times to the present. New York: Harley Moon, 2006.

WILLIANS, C. The destruction of black civilization: great issues of a race from 4500 B.C. to 2000 A.D. Chicago: Third World Press, 1987.

Recebido em 15.06 .09

Aprovado em 04.05.10

Douglas Verrangia pertence ao Núcleo de Estudos Afro-brasileiros, grupo de pesquisas Práticas Sociais e Processos Educativos da UUniversidade Federal de São Carlos. É biólogo, mestre e doutor em Educacão, professor adjunto do Centro de Ciências Agrárias da UFSCar, e tem experiência na área de formação de professores de Ciências e Biologia.

Petronilha Beatriz Gonçalves e Silva pertence ao Núcleo de Esstudos Afro-brasileiros, grupo de pesquisas Práticas Sociais e Processos Educativos dả Universidade Federal de São Carlos. É mestre e doutora em Educação, professora titular da UFSCar, departamento de Metodologia de Ensino, foi conselheira do Conselho Nacional de Educação e atualmente é presidente do grupo gestor do Programa de Ações Afirmativas da mesma universidade. E-mail: dpbs@ufscar.br. 